\title{
Correction to: The effect of successive low-impact development rainwater systems on peak flow reduction in residential areas of Shizhuang, China
}

\author{
Zhan-Tang Miao ${ }^{1} \cdot$ Mooyoung Han $^{2} \cdot$ Shervin Hashemi ${ }^{2}$
}

Published online: 2 February 2019

๑) Springer-Verlag GmbH Germany, part of Springer Nature 2019

\section{Correction to: Environmental Earth Sciences (2019) 78:51 https://doi.org/10.1007/s12665-018-8016-z}

In the original publication, the Figs. 5 and 7 are published incorrectly. The correct figures are given below:

The original article has been updated.

The original article can be found online at https://doi.org/10.1007/ s12665-018-8016-z.

Zhan-Tang Miao

miaozhantang@tju.edu.cn

1 School of Architecture, Tianjin University, Tianjin 300072, China

2 Department of Civil and Environmental Engineering, Seoul National University, Seoul 08826, Republic of Korea 
Fig. 5 a Runoff comparison between different systems for 2-year return period rainfall, b runoff comparison between SLIDRS with and without rain barrels for 2-year return period rainfall, and $\mathbf{c}$ daily water balance comparison between SLIDRS with and without rain barrels (a)

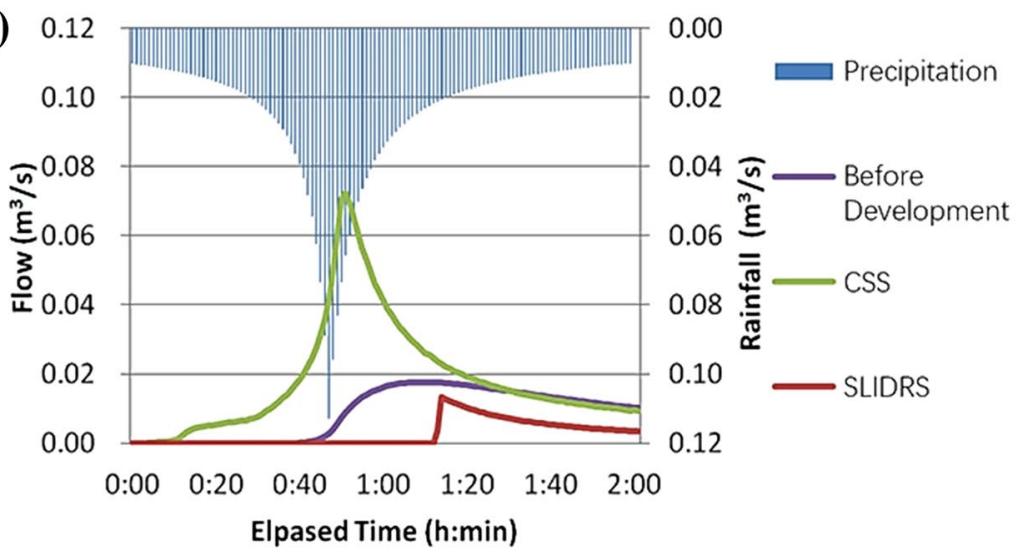

(b)

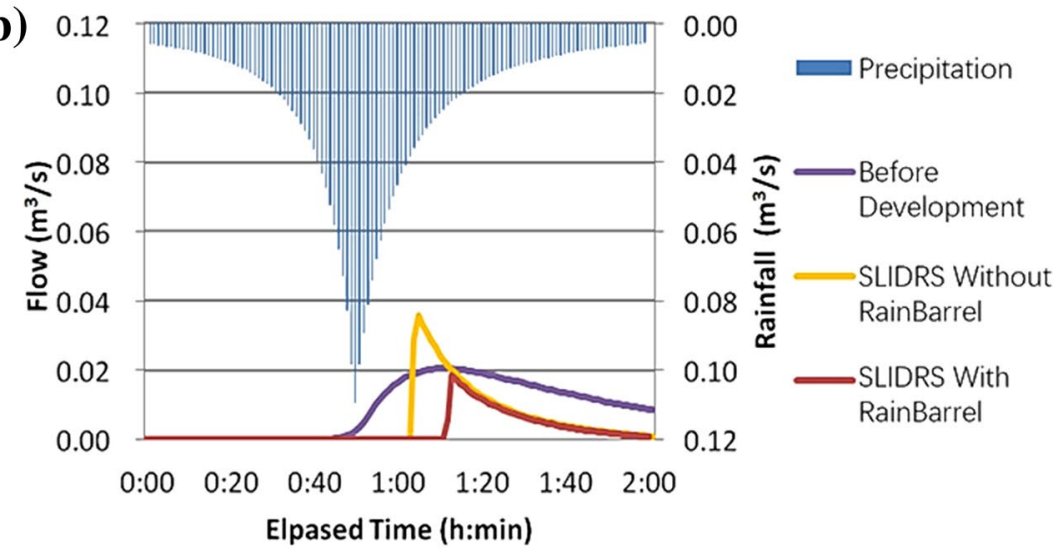

(c)

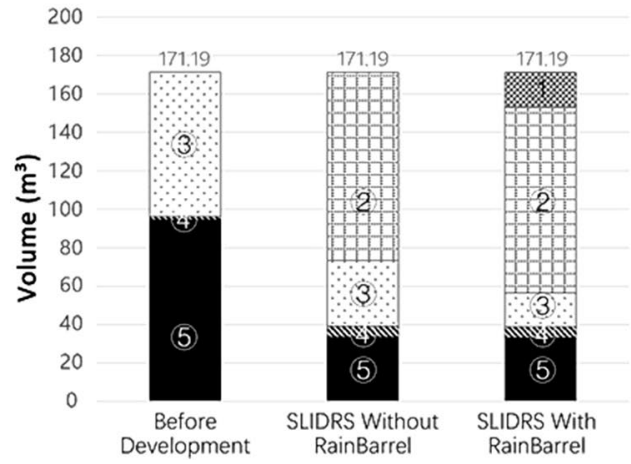

(1) RainBarrel Storage

曲 (2) Other LID Storage

종 (3) Surface Flow

(4) Evaporation

(5) Infiltration 
Fig. 7 a Effects on infiltration, b the daily water balance, and $\mathbf{c}$ rain garden soil moisture (a)

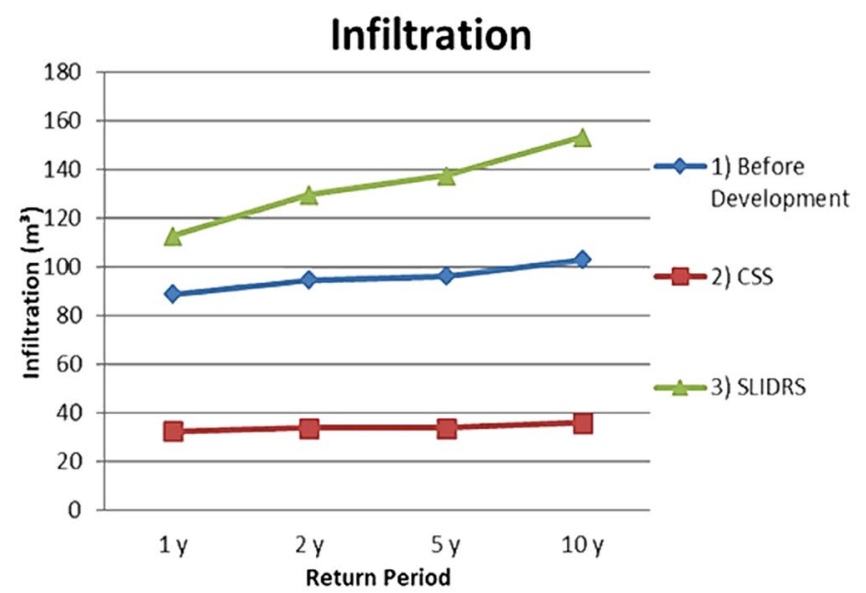

(b)
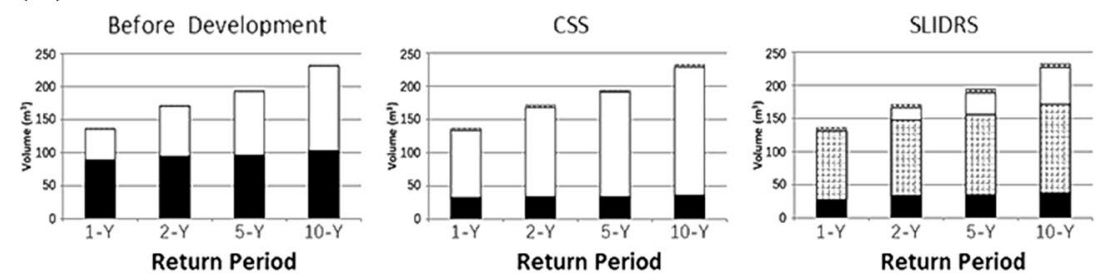

Evaporation

$\square$ surface Flow

Infiltration

(c)

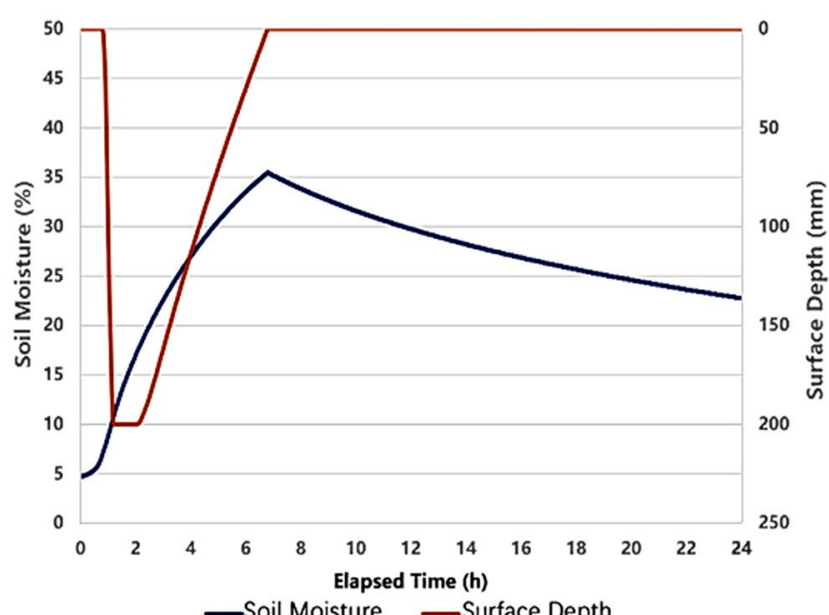

Publisher's Note Springer Nature remains neutral with regard to jurisdictional claims in published maps and institutional affiliations. 